\title{
Effect of acute hyperoxia on the bronchodilator response to salbutamol in stable asthmatic patients
}

\author{
Kenneth D Dagg, Lorna J Thomson, Scott G Ramsay, Neil C Thomson
}

\begin{abstract}
Background - Recent animal studies have suggested that changes in oxygen tension may alter airway responses to bronchoconstrictor and bronchodilator stimuli. These effects may have relevance to the management of acute exacerbations of asthma but have not been well studied in man. This study was designed therefore to examine the effect of acute hyperoxia $\left(\mathrm{FiO}_{2} \mathbf{1 . 0}\right)$ on the bronchodilator response to salbutamol in stable asthmatic patients. Methods - Twelve stable adult asthmatic patients (three women) were studied using a randomised double blind placebo controlled crossover design. On two study days following baseline measurements patients breathed either air $\left(\mathrm{Fio}_{2} \mathrm{0.21}\right)$ or oxygen $\left(\mathrm{FiO}_{2} 1.0\right)$ for 10 minutes alone and then in combination with three incremental doses of nebulised salbutamol administered at 15 minute intervals. The same protocol was employed on two further study days using nebulised saline instead of salbutamol.
\end{abstract}

Results - The mean absolute change in forced expiratory volume in one second $\left(F E V_{1}\right)$ from baseline after salbutamol was similar on the normoxic and hyperoxic study days but significantly greater than the study days on which nebulised saline was administered.

Conclusion - Acute hyperoxia does not potentiate the immediate bronchodilator response to salbutamol in stable asthmatic patients.

(Thorax 1996;51:853-854)

Keywords: hyperoxia, salbutamol, asthma.

Recent studies have suggested that changes in airway oxygen tension may alter the influence of bronchoconstrictors and bronchodilators on airway tone. ${ }^{12}$ Acute hyperoxia has been shown in vitro to attenuate methacholineinduced ${ }^{1}$ bronchoconstriction in isolated bovine bronchial rings and in vivo to relieve exercise-induced bronchoconstriction. ${ }^{3}$ Hyperoxia may also potentiate the effect of bronchodilators such as salbutamol in vitro. ${ }^{1}$ No previous studies have investigated the effect of acute hyperoxia on bronchodilator responses in man. If acute hyperoxia can alter the airway response to bronchodilators such as salbutamol, then the administration of high inspired oxygen concentrations during acute exacerba- tions of asthma may not only improve gas exchange, but could also enhance the effect of bronchodilators. The present study was designed to examine the effect of acute hyperoxia on the bronchodilator response to salbutamol in patients with asthma.

\section{Methods}

Twelve adult asthmatic patients (three women) with a mean (SD) age of 47 (14) years and forced expiratory volume in one second $\left(\mathrm{FEV}_{1}\right)$ of $2.05(0.6)$ litres (79 (17)\% predicted) were recruited into the study. On four study days after 30 minutes of supine rest patients were commenced on a closed breathing circuit. Following a 10 minute run-in period during which patients breathed air $\left(\mathrm{FiO}_{2} \mathrm{0.21}\right)$, baseline measurements of $\mathrm{FEV}_{1}$, oxygen saturation $\left(\mathrm{SaO}_{2} \%\right)$, respiratory rate, heart rate, and inspired and expired oxygen and carbon dioxide levels (\%) were made. Venous blood was also taken for assay of plasma catecholamines. Patients were then randomised to receive either air $\left(\mathrm{FiO}_{2} 0.21\right)$ on two study days or oxygen $\left(\mathrm{FiO}_{2} 1.0\right)$ on the remaining two study days. The gases were administered in a randomised double blind fashion. Following a further 10 minutes breathing the study gas through the closed breathing circuit, the patients received either three incremental concentrations of nebulised salbutamol $(0.05 \mathrm{mg} / \mathrm{ml}, 0.17 \mathrm{mg} / \mathrm{ml}, 5 \mathrm{mg} / \mathrm{ml})$ or placebo (normal saline) at 15 minute intervals, again in a double blind fashion. Baseline measurements were repeated 13 minutes after each nebulisation until completion of the study day. All patients gave written informed consent to the study and the protocol was approved by the West ethics committee.

DATA ANALYSIS

Analysis of variance (ANOVA) corrected for multiple comparisons was used to compare measurements made at baseline and following each dose of nebulised saline or salbutamol.

\section{Results}

There were no significant differences in baseline measurements between the study days (table 1). The mean absolute change in $\mathrm{FEV}_{1}$ from baseline after salbutamol was similar on both the normoxic and hyperoxic study days but significantly greater $(p<0.01)$ than the study days in which nebulised saline was 
Table 1 Mean (SE) baseline measurements of respiratory rate, heart rate, inspired and expired oxygen and carbon dioxide levels, and plasma catecholamine levels for each study day

\begin{tabular}{|c|c|c|c|c|}
\hline \multirow[b]{2}{*}{ Baseline measurements } & \multicolumn{2}{|c|}{$\operatorname{Air}\left(\mathrm{FiO}_{2} 0.21\right)$} & \multicolumn{2}{|c|}{ Oxygen $\left(\mathrm{FiO}_{2}\right.$ 1.0) } \\
\hline & Placebo & Salbutamol & Placebo & Salbutamol \\
\hline $\mathrm{FEV}_{1}(\mathrm{l})$ & $2.06(0.21)$ & $2.07(0.23)$ & $2.06(0.21)$ & $1.98(0.21)$ \\
\hline Heart rate (beats/min) & $77 \quad(3.0)$ & $78 \quad(4.4)$ & $75 \quad(2.6)$ & $76 \quad(3.1)$ \\
\hline Respiratory rate (breaths/min) & $13.8(1.03)$ & $(0.78)$ & $14.5(0.84)$ & $15.1(1.36)$ \\
\hline Oxygen saturation $(\%)$ & $96 \quad(0.59)$ & $(0.49)$ & $96 \quad(0.32)$ & $96 \quad(0.42)$ \\
\hline Inspired $\mathrm{O}_{2}(\%)$ & $21 \quad(0)$ & $21 \quad(0)$ & $21 \quad(0)$ & (0) \\
\hline Expired $\mathrm{O}_{2}(\%)$ & $16.4 \quad(0.34)$ & $16.5(0.29)$ & $16.5(0.34)$ & $16.4(0.31)$ \\
\hline Expired $\mathrm{CO}_{2}(\%)$ & $4.31(0.21)$ & $4.20(0.19)$ & $4.49(0.25)$ & $4.50(0.15)$ \\
\hline Plasma noradrenaline $(\mathrm{nmol} / \mathrm{l})$ & $1.94(0.43)$ & $2.34(0.44)$ & $2.23(0.46)$ & $2.18(0.36)$ \\
\hline Plasma adrenaline (nmol/l) & $0.10(0.02)$ & $0.11(0.02)$ & $0.10(0.02)$ & $0.12(0.02)$ \\
\hline
\end{tabular}

No significant differences were seen between any of the study days.

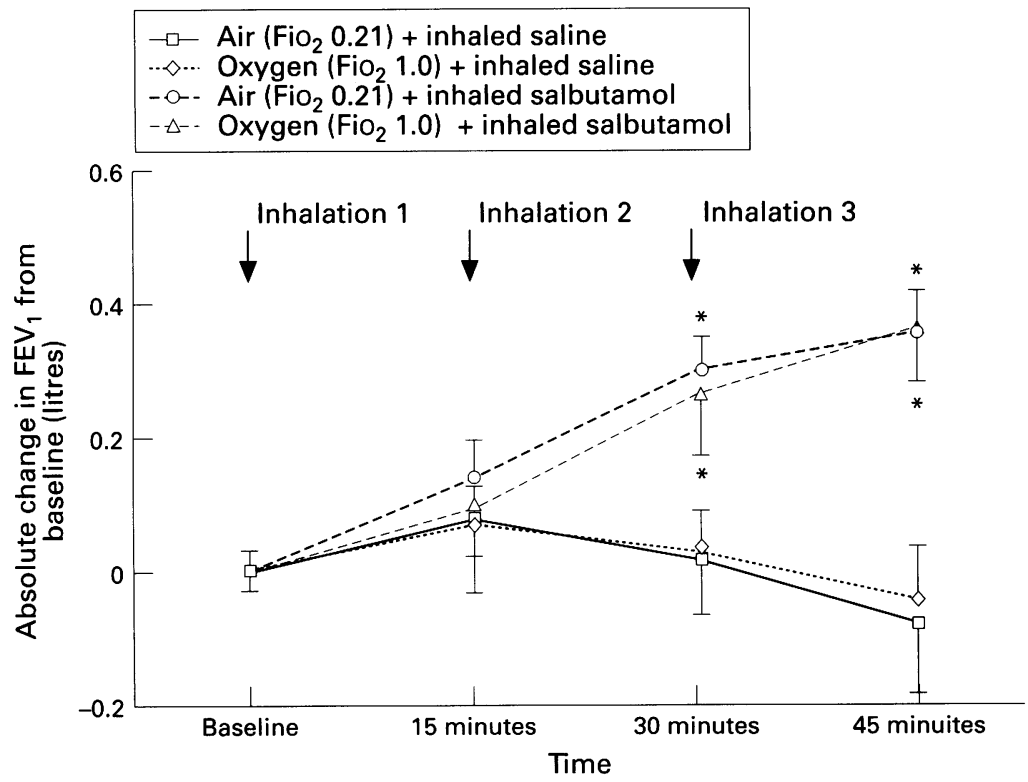

Figure 1 Effect of nebulised salbutamol or saline (inhalation 1: salbutamol $0.05 \mathrm{mg} / \mathrm{ml}$ or saline; inhalation 2: salbutamol $0.17 \mathrm{mg} / \mathrm{ml}$ or saline; inhalation 3: salbutamol $5 \mathrm{mg} / \mathrm{ml}$ or saline) on absolute change in $\mathrm{FEV}$, (litres) from baseline whilst breathing air $\left(\mathrm{FiO}_{2} 0.21\right)$ or oxygen $\left(\mathrm{FiO}_{2} 1.0\right)$ in 12 asthmatic patients. $* p<0.01$ salbutamol versus saline at each time point.

administered (fig 1). There were significant ( $p$ $<0.01$ ) increases in oxygen saturation on both the hyperoxic study days at 15,30, and 45 minutes when compared with the normoxic study days (mean (SE) $\mathrm{SaO}_{2} \%$ at 45 minutes: hyperoxia/salbutamol study day $97.7(0.5) \%$; normoxia/salbutamol study day $96.0(0.5) \%)$. The mean absolute fall in heart rate from baseline was significantly greater $(p<0.05)$ on the hyperoxia/salbutamol study day at 15,30 , and 45 minutes than on the normoxia/salbutamol study day (mean (SE) absolute fall in heart rate (beats per minute) at 45 minutes: hyperoxia/ salbutamol -5.2 (1.3) bpm; normoxia/ salbutamol -2.1 (1.3) bpm). The mean (SE) expired carbon dioxide levels were significantly lower ( $p<0.05$ ) on the hyperoxia/placebo study day (3.9 $(0.2) \%$ than on the normoxia/ placebo day $(4.2(0.2) \%)$ at 45 minutes only, but were similar at all time points on the study days on which salbutamol was administered. There were no significant differences in plasma catecholamine levels between study days.

\section{Discussion}

These results indicate that acute hyperoxia does not potentiate the effect of nebulised salbutamol in stable asthmatic patients over one hour. The rise in oxygen saturation and fall in heart rate ${ }^{4}$ observed on the hyperoxic study days would suggest that our closed breathing circuit had achieved a high inspired oxygen tension. Alterations in circulating catecholamine and end tidal carbon dioxide levels may have effects on airway tone. ${ }^{56}$ We detected no significant change in plasma catecholamine or end tidal carbon dioxide levels between the study days on which nebulised salbutamol was administered, which suggests that these factors did not influence our results.

The difference between the in vitro and in vivo findings may be accounted for by species variation. Whilst acute hyperoxia attenuates methacholine-induced bronchoconstriction in bovine bronchial rings, ${ }^{1}$ this effect is not observed in rat bronchial rings. ${ }^{2}$ Hyperoxia may itself have effects on airway tone, via neural pathways, which offset any potentially beneficial effects that hyperoxia may have on the bronchodilator response to salbutamol. However, we found no significant change in $\mathrm{FEV}_{1}$ following the administration of hyperoxia alone.

We have examined the effect of acute hyperoxia on salbutamol over a period of one hour. It is possible that, if hyperoxia alters drug receptor binding, causes upregulation of $\beta_{2}$ adrenoceptors, or alters intracellular metabolic pathways causing smooth muscle relaxation, these effects may develop after a period of more than 60 minutes. We suggested that, if acute hyperoxia potentiates the effect of salbutamol, it may have relevance to the management of acute exacerbations of asthma. Such patients are often hypoxic and it is possible that any potentiating effect of hyperoxia on the bronchodilator response to salbutamol may only occur when hypoxic patients are rendered hyperoxic.

We conclude that acute hyperoxia does not potentiate the immediate bronchodilator response to nebulised salbutamol in stable asthmatic patients.

This study was supported by a grant from the British Lung Foundation.

1 Clayton RA, Nally JE, Thomson NC, McGrath JC. The effect of oxygen tension on responses evoked by methaeffect of oxygen tension on responses evoked by metha-
choline and bronchodilators in isolated bovine bronchial choline and bronchodilators in isolate
rings. Pulm Pharmacol 1996 (in press).

2 Clayton RA, Nally JE, Maclean MR, Thomson NC McGrath JC. The effect of acute changes in $\mathrm{O}_{2}$ tension on responses to methacholine in bronchi from chronically hypoxic rats. Thorax 1994;50:475P.

3 Schiffman PL, Ryan A, Whipp BJ, Hansen JE. Hyperoxic attenuation of exercise induced bronchospasm in asthmatics. $\mathcal{F}$ Clin Invest 1979;63:30-7.

4 Watt JG, Dumke PR, Comroe Jr JH. Effects of inhalation of 100 per cent and 14 per cent oxygen upon respiration of unanesthetized dogs before and after chemoreceptor denervation. Am $\mathcal{F}$ Physiol 1942;138:610-7.

5 Newhouse MT, Becklake MR, Macklem PT, McGregor M Effect of alterations in end-tidal $\mathrm{CO}_{2}$ tension on flow resistance. $\mathcal{F} A p p l$ Physiol 1964;19:745-9.

6 Thomson NC, Dagg KD, Ramsay SG. Humoral control of airway tone. Thorax 1996;51:461-4. 